\title{
Correction to: Systemic Therapy of Central Nervous System Metastases of Breast Cancer
}

\author{
José Pablo Leone ${ }^{1} \cdot$ Nancy U. Lin ${ }^{1}$ \\ Published online: 17 May 2019 \\ (C) Springer Science+Business Media, LLC, part of Springer Nature 2019
}

\section{Correction to: Curr Oncol Rep (2019) 21:49 https://doi.org/10.1007/s11912-019-0802-6}

The original version of this article, which published in Current Oncology Reports, Volume 21, Issue 6, June 2019, contained an error in addressing the indication for use of neratinib in early stage breast cancer. In the final paragraph of page 3 , under the "HER2-Positive Disease" heading, the authors originally stated that "neratinib's label in the USA is for the treatment of high-risk early breast cancer only, pending results of the phase III trial of neratinib plus capecitabine vs. lapatinib plus capecitabine (NALA) in the metastatic setting." According to the package insert, neratinib "is a kinase inhibitor indicated for the extended adjuvant treatment of adult patients with early stage HER2-overexpressed/ amplified breast cancer, to follow adjuvant trastuzumab-based therapy."

The authors apologize to the readers for this error.

Publisher's Note Springer Nature remains neutral with regard to jurisdictional claims in published maps and institutional affiliations

The online version of the original article can be found at https://oi.org/ 10.1007/s11912-019-0802-6

José Pablo Leone

josep_leone@dfci.harvard.edu

1 Department of Medical Oncology, Division of Breast Oncology, Dana-Farber Cancer Institute, Harvard Medical School, 450

Brookline Ave., Boston, MA 02215, USA 